\title{
Peer gender and STEM specialization *
}

\author{
Greta Morando ${ }^{\dagger}$
}

\begin{abstract}
This paper shows that students are less likely to specialize in mathematics when exposed to a high share of male peers. I exploit a curricular reform that incentivized students to obtain a mathematics qualification post-16. I show that, for those students affected by the reform, the higher the share of same-gender classmates, the higher the likelihood of obtaining a mathematics qualification for boys, and the lower the likelihood for girls. I interpret this as suggestive evidence that one's perceived ability in mathematics, a boydominated subject, decreases when the share of male classmates increases. This further affects STEM participation in higher education.
\end{abstract}

Keywords: female participation in STEM, peer effects, school curricular reform, degree choice.

JEL Classification: J16, I28, I23.

${ }^{*}$ I am grateful to Thomas Cornelissen for a useful discussion and to an anonymous referee for his/her comments that improved this paper. I acknowledge the support of the ESRC Postdoctoral Research Fellowship (award no. ES/S011900/1). The data is supplied by the Department for Education and the Higher Education Statistics Agency. The author will provide guidance on obtaining the data. The use of the data in this work does not imply the endorsement of any of the organizations cited above in relation to the interpretation or analysis of the data. All remaining errors are my own.

${ }^{\dagger}$ Royal Holloway University of London; e-mail:greta.morando@rhul.ac.uk. 


\section{Introduction}

The gender composition of peers has been found to be an important factor that affects student selection into STEM ${ }^{1}$ fields (Brenoe and Zölitz, forthcoming, Anelli and Peri, 2019; Favara, 2012). This paper investigates whether an environment with a high share of same-gender peers affects the likelihood of obtaining a mathematics qualification post-16 in England, where students decide the subjects to study at this stage of education.

I introduce a novel way of addressing this question by combining the empirical strategy largely used in the peer effect literature (which exploits the quasi-random variation of peer exposure across cohorts within school or class) with a quasi-experimental setting. I exploit a reform that promoted the study of mathematics post-16 by decreasing the cost of studying it through a reduction in the curricular program.

Morando (2020) provides an extensive analysis of the effects of this reform at school and higher education. This shows that the reform resulted in an increase in the likelihood of acquiring a mathematics qualification at 18 years old (A-level mathematics) mainly driven by an increase in the likelihood of students choosing to study mathematics at 16 . As result of this, students acquiring a mathematics qualification increased their enrollment and graduation in STEM and Economics degrees. In this paper, I exploit the same reform as a positive incentive to acquire a mathematics qualification and I test whether this is affected by the share of same-gender classmates.

I focus on high achieving students in mathematics attending mixed-sex secondary schools and find that the likelihood of obtaining a mathematics qualification for those cohorts affected by the reform increases with exposure to same-gender peers for boys, while it decreases for girls. In other words, the marginal students that acquired a mathematics qualification because of a decrease in the difficulty of studying it, are those exposed to a large share of male classmates.

\footnotetext{
${ }^{1}$ Science, Technology, Mathematics and Engineering.
} 
I argue that this finding is consistent with the perception of one's own mathematics ability decreasing as the share of male classmates increases. The confidence of students in their own ability in certain subjects has indeed been found to be influenced by the social environment which students are exposed to, and to influence their educational choices in the long run (Murphy and Weinhardt, forthcoming; Carlana, 2019; Cools et al., 2019).

Finally, I also show that for both boys and girls exposed to a higher share of male classmates after the reform (which are those more likely to have increased their likelihood in obtaining a mathematics qualification at 18) there is an increase in the likelihood of obtaining a STEM undergraduate degree at university. Thus, exposure to gender peers at school has long-lasting effects on student specialization in STEM fields.

\section{Data and institutional settings}

I use the National Pupils Database linked to the Higher Education Student Record. This provides information about the universe of students in all English schools. I can follow each individual that obtained a qualification in junior high school (age 11 to 16) between 2002 to 2007 up to university. At junior high school mathematics is compulsory. At senior high school, students can instead decide whether to study it. I am thus interested in whether students obtained a mathematics qualification at senior high school as a result of a curricular reform that promoted such behavior and whether this is affected by the gender composition in the classroom at junior high school.

The reform studied herein consisted of a sudden decrease in the content of the mathematics curriculum at senior high school by $1 / 5$. The cohorts 2004 to 2007 are those affected by such reform. Since I am interested in the share of same-gender classmates I keep mixed-sex schools only. As the possibility of studying mathematics post-16 depends on the grade acquired at junior

high school, I retain only those students that could have studied mathematics post-16, i.e. those 
who obtained an $\mathrm{A}^{*}$ to $\mathrm{B}$ grade in mathematics in junior high school. ${ }^{2}$

To define the share of same-gender peers (constructed as the leave-me-out mean, Angrist 2014), I consider two samples: the first includes all students within school and cohort, and the second the students within the same cohort and classroom of mathematics. ${ }^{3}$

\section{Empirical strategy}

I test whether there is a statistically significant relation between the share of same-gender peers and the likelihood of obtaining a mathematics qualification when the expected effort of studying the subject decreases. I compare the behavior of students exposed to the same share of same-gender peers in the pre-reform cohorts (2002-2003) to the behavior of those in the post-reform cohorts (2004-2007).

$$
y_{i s t}=\beta_{0}+\beta_{1} \text { ShSameGender }_{s}+\beta_{2}\left(\text { ShSameGender }_{s} * \text { Post }_{t}\right)+\lambda_{s}+\phi_{t}+e_{i s t} .
$$

Equation 1 is estimated as a linear probability model. The outcome is whether obtained a mathematics qualification at 18 and $\beta_{2}$ is the coefficient of interest to be estimated. Subscript $i$ stands for individual, $s$ for school, and $t$ for cohort. The Post dummy variable assumes the value of 1 for those students who finished junior high school in years 2004-2007; $\lambda_{s}$ and $\phi_{t}$ are school and cohort fixed effects, respectively.

The underlying assumption for the identification strategy just exposed to be valid is that the share of same-gender peers within school across time is as good as a random conditional on

\footnotetext{
${ }^{2}$ Morando (2020) shows that there is no clear evidence of the reform affecting this margin. Indeed, this sample restriction does not affect the results since when I consider the whole sample the findings hold.

${ }^{3}$ The latter is inferred by exploiting the way in which the educational system is structured. In the period here considered the system of teaching and assessing mathematics at junior high school was a 3-tier system. Students were divided into three different classes where the material studied and the exam papers differed in their complexity. Foundation is the lowest tier and grades here range from D to G. In the intermediate tier grades vary from $B$ to $E$ and in the higher from $A^{*}$ to $C$. The sample is composed of students with a mathematics grade $\mathrm{A}^{*} / \mathrm{B}$ and I define their classmates as those students with a mathematics grade $\mathrm{A}^{*} / \mathrm{C}$ (higher tier) in the same school and cohort.
} 
Figure 1: Share of high achieving students with a mathematics qualification at senior high school by share of same-gender peers at junior high school
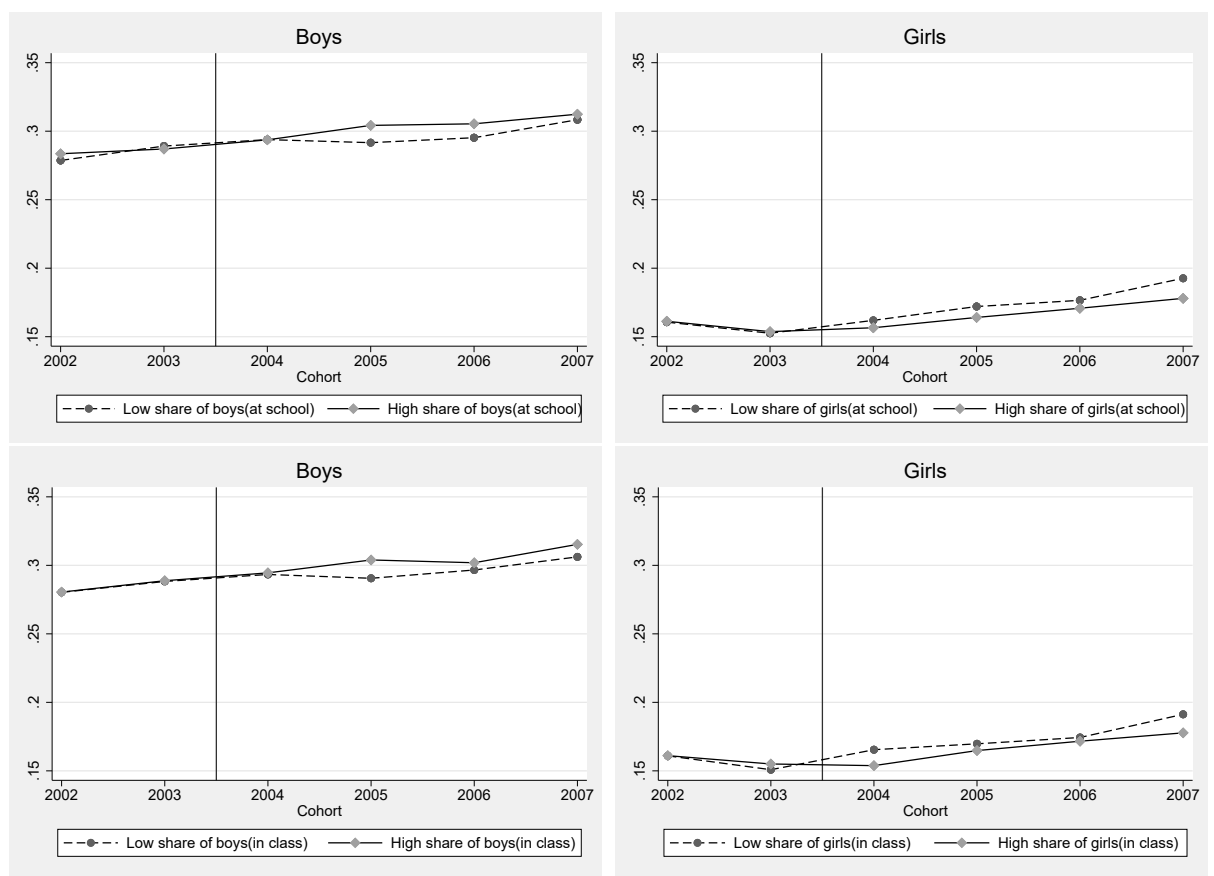

cohort and school fixed effects. Following the literature on peer effects, I regress individual predetermined characteristics on female student share with school and cohort fixed effects. There is no correlation of share of female students with a series of student characteristics such as ethnicity and their socio-economic status. ${ }^{4}$ In the empirical analysis outlined in Equation 1 I additionally condition on total number of students as well as on individual characteristics; even through when including these covariates the results are not affected. Importantly, I also condition on the actual academic performances of students to account for their academic ability by using the primary school mathematics score and the capped score (i.e. the weighted sum of the grades achieved at junior high school). Both scores are transformed into deciles within each cohort to account for grade inflation.

In Figure 1, I inspect the time trends of obtained mathematics qualifications at senior high school for high achieving students when the share of same-gender peers at junior high school is

\footnotetext{
${ }^{4}$ Results available upon request.
} 
just above/below its median value. For both boys and girls, pre-reform time trends and levels are similar for the two groups. For the students affected by the reform, there is a sign of an increase in the gap between students exposed to a high and a low share of same-gender peers.

\section{Results}

The first panel of Table 1 shows that for both boys and girls in the post-reform cohorts there is an increase in the likelihood of obtaining a mathematics qualification at senior high school of about 4 and 9 percent compared to the pre-reform mean.

I investigate next whether this behavior is affected by the gender of peers. Table 1 shows the estimates of the analysis described in Equation 1 when using the same-gender share at school level (panel 2) and at class level (panel 3). As results are similar, I discuss those in panel 3. After the reform, a one percentage point (ppt) increase in the share of boy classmates at junior high school increases the likelihood of obtaining a mathematics qualification at senior high school by $0.07 \mathrm{ppt}$ for boys and $0.05 \mathrm{ppt}$ for girls. An increase in the same-gender share from its minimum to its median value ${ }^{5}$ implies an increase (decrease) in mathematics qualification of about 4ppt (3ppt) for boys (girls); this is equivalent to a $12 \%$ (17\%) effect compared to the pre-reform mean. When I introduce same-gender peers in tertiles, it is clear that the increase in obtained mathematics qualifications happened for those boys and girls exposed to a higher share of same-gender peers in a monotonic manner.

To interpret these findings it is important to notice that it is very unlikely that schools had the possibility to respond to the reform by adjusting their resources as this was implemented suddenly and there was a lot of uncertainty about its possible outcomes. Cohort fixed effects account for other phenomena, such as other educational policies, which might have affected the outcome of interest independently of the reform. School fixed effects allow us to condition on

\footnotetext{
${ }^{5}$ The median of same-gender peers in the mathematics class is 0.486 for boys and 0.522 for girls; the minimum value is zero for both boys and girls.
} 
Table 1: Whether obtained a mathematics qualification at senior high school

\begin{tabular}{lcc}
\hline \hline & Boys & Girls \\
\hline Panel 1 & & \\
Post & $0.013^{* * *}$ & $0.015^{* * *}$ \\
& $(0.002)$ & $(0.002)$ \\
Panel 2 & & \\
Post*ShSameGender ${ }^{\text {school }}$ & $0.085^{* * *}$ & $-0.059^{* * *}$ \\
& $(0.021)$ & $(0.020)$ \\
Panel 3 & & \\
Post*ShSameGender ${ }^{\text {class }}$ & $0.073^{* * *}$ & $-0.054^{* * *}$ \\
& $(0.020)$ & $(0.019)$ \\
Panel 4 & & \\
Post*ShSameGender & \\
& $-0.015^{* * *}$ & $0.012^{* * *}$ \\
Post*ShSameGender ${ }^{\text {school }}$ Q2 & $(0.006)$ & $(0.004)$ \\
& $-0.010^{*}$ & 0.005 \\
Panel 5 & $(0.006)$ & $(0.004)$ \\
Post*ShSameGender ${ }^{\text {class }}$ Q1 & $-0.012^{* *}$ & $0.010^{* *}$ \\
Post*ShSameGender ${ }^{\text {class }}$ Q2 & $(0.005)$ & $(0.004)$ \\
& $-0.010^{*}$ & 0.005 \\
& $(0.006)$ & $(0.004)$ \\
Observations & & \\
Pre-reform mean Y & 339,300 & 342,800 \\
\hline \hline
\end{tabular}

Notes: every panel represents a separate regression. Covariates included in all specifications: ethnicity, Special Educational Needs, Free School Meal eligibility, English is first language, Index of Multiple Deprivation deciles, academic ability deciles at secondary school and mathematicsspecific ability deciles at primary school. KS5 school and cohort fixed effects included. Additionally, in the specifications of panel 2 to 5 other covariates included are: post dummy, share of same-gender (panel 2 and 3), and total number of schoolmates (panel 2 and 4 ) or classmates (panel 3 and 5). In the specifications of panel 4 and 5 the omitted category is the highest quantile of share of same-gender peer (Q3). The standard errors are clustered by school and reported in parentheses. ${ }^{*} \rho<0.1{ }^{* *} \rho<0.05 * * * \rho<0.01$. 
school average quality of students and of teachers, ${ }^{6}$ and on typical school culture about gender stereotypes. Furthermore, the analysis conditions on academic performances to account for the actual ability of students. Finally, when I include as additional covariate the current same-gender share in the mathematics classroom at senior high school the findings above hold.

Given the above considerations, I interpret the results of the analysis as suggestive evidence that the perception that students have of their own mathematics ability decreases as the share of male classmates increases. Indeed, those who specialized in mathematics when the cost of studying mathematics decreased are boys and girls who were exposed to a high share of male classmates.

Table 2: Whether graduated in a STEM undergraduate degree

\begin{tabular}{lcc}
\hline \hline & Boys & Girls \\
\hline Panel 1 & & \\
Post*ShSameGender & & \\
& $(0.019)$ & $(0.020)$ \\
Panel 2 & & \\
Post*ShSameGender $^{\text {class }}$ & $0.070^{* * *}$ & $-0.042^{* *}$ \\
& $(0.018)$ & $(0.019)$ \\
& & \\
Observations & 339,300 & 342,800 \\
Mean Y & 0.279 & 0.203 \\
\hline \hline
\end{tabular}

Notes: As for panel 2 and 3 of Table 1.

Finally, Table 2 shows that boys exposed to a larger share of same-gender peers after the reform are more likely to graduate in a STEM degree (vs. not graduate at all or graduate in other fields) by $0.07 \mathrm{ppt}$ while for girls there is a negative effect on this outcome of $0.04 \mathrm{ppt}$. This suggests that exposure to different shares of same-gender peers at junior high school has long-lasting consequences on human capital acquisition.

\footnotetext{
${ }^{6}$ The data does not have information on teachers so I cannot include teacher fixed effects. However, the fact that mathematics teachers at secondary school have a low turnover (as their national supply is very low, The Royal Society, 2007) means that the school fixed effect partly accounts for teacher characteristics. When the analysis is repeated for small schools, where school fixed effect is very likely to be equivalent to a teacher fixed effect, results hold.
} 


\section{Conclusion}

By using a quasi-experimental approach, which implied a decrease in the cost of effort in studying mathematics, combined with idiosyncratic variation of exposure to same-gender peers, this paper provides novel evidence of the relevance of the social environment, and more specifically the exposure to the gender of peers, on field of study specialization. The increase in mathematics qualifications after this subject became less demanding occurred among students exposed to a high share of male classmates. I interpret this as suggestive evidence that for those fields dominated by one gender, the higher the exposure to that gender the less likely students are to specialize in it. I further show that this has consequences in the educational careers of individuals in the long-run.

\section{References}

Anelli, M. and G. Peri (2019). The effects of high school peers' gender on college major, college performance and income. The Economic Journal 129(618), 553-602.

Angrist, J. D. (2014). The perils of peer effects. Labour Economics 30, 98-108.

Brenoe, A. A. and U. Zölitz (forthcoming). Exposure to more female peers widens the gender gap in STEM participation. Journal of Labor Economics.

Carlana, M. (2019). Implicit stereotypes: Evidence from teachers' gender bias. The Quarterly Journal of Economics 134(3), 1163-1224.

Cools, A., R. Fernández, and E. Patacchini (2019). Girls, boys, and high achievers. No. w25763. National Bureau of Economic Research.

Favara, M. (2012). The cost of acting "girly": Gender stereotypes and educational choices. IZA Discussion Paper No. 7037.

Morando, G. (2020). The effect of studying mathematics on major choice. Mimeo.

Murphy, R. and F. Weinhardt (forthcoming). Top of the class: The importance of ordinal rank. Review of Economic Studies.

The Royal Society (2007). The UK's science and mathematics teaching workforce. The Royal Society. 